This item was submitted to Loughborough's Research Repository by the author.

Items in Figshare are protected by copyright, with all rights reserved, unless otherwise indicated.

\title{
Association of anthropometric indices of nutritional status with growth in height among Limboo children of Sikkim, India
}

PLEASE CITE THE PUBLISHED VERSION

https://doi.org/10.1127/anthranz/2020/1174

\section{PUBLISHER}

Schweizerbart Science Publishers

\section{VERSION}

VoR (Version of Record)

\section{PUBLISHER STATEMENT}

This is an Open Access Article. It is published by Schweizerbart Science Publishers under the Creative Commons Attribution-NonCommercial 4.0 International Licence (CC BY-NC). Full details of this licence are available at: https://creativecommons.org/licenses/by-nc/4.0/

\section{LICENCE}

CC BY-NC 4.0

\section{REPOSITORY RECORD}

Dorjee, Binu, Barry Bogin, Christiane Scheffler, Detlef Groth, Jaydip Sen, and Michael Hermanussen. 2020. "Association of Anthropometric Indices of Nutritional Status with Growth in Height Among Limboo Children of Sikkim, India”. Loughborough University. https://hdl.handle.net/2134/13237952.v1. 


\title{
Association of anthropometric indices of nutritional status with growth in height among Limboo children of Sikkim, India
}

\author{
Binu Dorjee ${ }^{1, *}$, Barry Bogin ${ }^{2,6}$, Christiane Scheffler ${ }^{3}$, Detlef Groth ${ }^{4}$, Jaydip Sen ${ }^{1}$, \\ and Michael Hermanussen ${ }^{5}$
}

\author{
1 University of North Bengal, Department of Anthropology, Raja Rammohunpur, Darjeeling, West Bengal 734013, India \\ 2 Loughborough University, School of Sport, Exercise and Health Sciences, LE11 3TU, UK \\ 3 University of Potsdam, Institute of Biochemistry and Biology/Human Biology, Potsdam, Germany \\ 4 University of Potsdam, Institute of Biochemistry and Biology/Bioinformatics Group, Potsdam, Germany \\ 5 Aschauhof 3, Eckernförde - Altenhof, Germany \\ 6 Member, UCSD/Salk Center for Academic Research and Training in Anthropogeny (CARTA), USA \\ * Corresponding author: kadelb@ymail.com
}

With 4 figures and 3 tables

\begin{abstract}
Aim: Influence of nutrition in human growth failure, especially stunting, is a well-accepted idea. The present study assesses the influence of nutrition and non-nutritional factors on height growth in a short stature population. Material and methods: The present study was conducted among the children and adolescents of Sikkim, India. The sample size was 538 (boys and girls) of age 2-18 years. The anthropometric indices mid upper arm circumference-for-age Z-scores (MUACZ) and BMI-for-age Z-scores (BAZ) were utilised as proxy of nutritional status and growth was assessed using height-for-age Z-scores (HAZ). Associations were assessed using correlation, St. Nicolas house analysis (SNHA), principal component analysis (PCA) and regression. Results: Nutritional status of the participating children and adolescents as assessed by MUACZ and BAZ were largely normal. Despite variation in HAZ from -4 to +2 there was no influence of the nutritional indices on height. Further, there was clear lack of association between HAZ and socio-economic variables in the present study. Conclusion: The findings of the present study suggest nutrition is not the primary regulator of human growth. The possible influence of community effects on height is discussed.
\end{abstract}

Keywords: stunting; short stature population; nutritional status; Sikkim; India

\section{Introduction}

Reporting prevalence of undernutrition among children and adolescents using anthropometric measurements and indices derived from height, weight, and other body measurements is a common and recommended practice (Jelliffe 1966; WHO 1995). The anthropometric measurements and indices are also utilised to assess overweight and obesity. The derived anthropometric indices are well accepted proxy measures of nutritional status and widely used (Chakraborty et al. 2011; Neufeld \& Osendarp 2014; Chirande et al. 2015; Demirchyan et al. 2016; Kinyoki et al. 2016; Singh et al. 2017). The Mid Upper-Arm Circumference (MUAC) is one such measurement frequently used to assess undernutrition. It is an alternative measure of nutritional status that can also be used in emergency situations like famine, war and feeding programs (WHO 1995; Sen et al. 2010; Reilly 2017). Other indices for nutritional assessment of thinness are MUAC-forage and MUAC-for-height based on Z-scores (de Onis et al. 1997). The MUAC is used with BMI for the assessment of thinness among adults for more precision (James et al. 1994; Chakraborty et al. 2011), and for upper-arm composition (Frisancho 1974; Jaswant \& Nitish 2014). Recently, MUAC was also put forth as an alternative to BMI-for-age Z-scores (BAZ) as a measure of overweight and obesity among children and adolescents (Craig et al. 2014; Chaput et al. 2017). The BAZ is frequently used as a proxy of thinness and obesity (de Onis et al. 2007; WHO 2007; Dorjee 2015). Sex specific BMI cut-offs for each age from 2-18 years are also provided in this regard. These references have been widely used as proxy of nutritional status especially for adiposity among children in line with adult BMI cut-offs points 
(Cole et al. 2000; Cole et al. 2007). The present study is an effort to assess the influence of nutrition on growth of children and adolescents. In absence of dietary information the anthropometric indices of nutritional status such as MUACZ, BAZ, and weight-for-age Z-scores (WAZ) were utilised.

A change in MUAC tends to parallel changes in muscle mass and fat mass and is a useful indicator of protein-energy nutritional status (Harries et al. 1985). Thus, changes in the arm circumference reflect the increase or decrease of tissue "reserves" of energy and protein in spite of its differential composition of fat, muscle, and bone (WHO 1995). It is used as a proxy of low fat free mass among children in resource poor setting (Reilly 2017). This simple measure of energy reserve can be regarded at par with the measure of skinfold thickness (Scheffler et al. 2018). So, the present study considers MUACZ, BAZ, and WAZ as measures of energy store in the human body, that is, as energy/nutritional status (Scheffler et al. 2020). According to prevailing notions, energy deficit or hunger during childhood and adolescence negatively influence growth, whereas well-fed youngsters have healthy growth. Growth in the present study is measured using height-for-age Z-scores (HAZ). There are however newer alternative perspectives on growth, one recently published paper titled "Stunting is not a synonym of malnutrition" (Scheffler et al. 2020) proposes that social and emotional factors unrelated with nutrition can regulate growth in height. In the present paper we test this new perspective. The hypothesis is that energy reserves in the body assessed by MUACZ, BAZ, and WAZ have no association with growth in height.

\section{Material and methods}

\section{The nature of the sample and area}

The state of Sikkim in the Indian Union is surrounded by three countries, Tibet, Bhutan, and Nepal. Sikkim borders the districts of Darjeeling and Kalimpong, West Bengal, India. Sikkim is mountainous and home to the world third highest peak, Mt. Kanchandzonga (8,586 m.a.s.1.). The Sikkim is inhabited by nearly twenty-five ethnic communities classified into four ethnic stocks (Lepcha, Limboo, Bhutia and Nepali). The participants of the present study mostly comprised of the Limboo children and adolescents. The Limboo exhibit East Asian biocultural features, like many Himalayan and North-east Indian populations (Dorjee et al. 2015).

The present community based cross-sectional study was carried out among 538 children and adolescents (boys: 277; girls: 261) aged between 2-18 years and residing in a rural area of West Sikkim. Initially children and adolescents included in the study were from Limboo as well as from other communities. However, only Limboo children and adolescents were considered for further analyses. Data were collected from November 2015 to March 2016 by visiting the Integrated Child Development Service (ICDS) centres, Private and Public schools located in Gyalshing (Geyzing) and Yangthang Block Administration area, of West Sikkim. Dates of birth of children were recorded from the school register. Approval of consent was taken from the local elected body and administration. An informed consent was also obtained from either parent of the children and school authorities. All the children were free from any physical deformities, clinical nutritional deficiency symptoms, and were not suffering from any diseases at the time of data collection.

\section{Anthropometric measurements and socio-economic information recorded}

Anthropometric measurements were recorded at schools, socio-economic information was provided by parents and teacher in case of young children and for older children by themselves. Infants' anthropometric measurements and socio-economic data were collected by visiting at ICDS centres. Measurements of height and weight were recorded following standard procedures (Weiner \& Lourie 1981). Height of the children was recorded using an anthropometer rod to the nearest $0.10 \mathrm{~cm}$ with bare feet. Weight of the children wearing minimum clothing and with bare feet was taken using a portable weighing scale to the nearest $0.10 \mathrm{~kg}$. MUAC was measured using flexible tape at the nearest $0.10 \mathrm{~cm}$. Intraobserver technical errors of the measurements (TEM) was calculated using the standard procedure of Ulijaszek \& Kerr (1999). The TEM was within the acceptable limit.

The socio-economic variables recorded were family monthly income (Income) in Indian currency (₹), father education (FEDU), mother education (MEDU), sib size (SSize), number of family member (FMmember), birth order (BROrder), house type (HCode), toilet type (Toil), drinking water (Water) and at least one government job in the family (GJob).

\section{Assessment of nutritional status and growth}

Z-score value of height, weight and BMI each were calculated using WHO Anthro plus software. Comprehensive reference by Frisancho (2008) was utilised to calculate MUAC-for-age Z-score (MUACZ). The derived indices utilised were HAZ, WAZ, BAZ, and MUACZ. Among these indices HAZ was used as indicator of growth in height and rest were used as indicators of nutritional status.

\section{Statistical analysis done}

Statistical analyses were undertaken using the SPSS Statistical Package (version 17.0) and R Gui (https://cran.rproject.org). Associations between variables were assessed using Spearman correlation, St. Nicolas' House Analysis, principal component analysis (PCA) and regression. The St. Nicolas' House Analysis (SNHA) technique is a new statistical method that helps translating correlation matrices into network graphs by tracing "association chains". Series of 
coefficients of determination that are characterized by the symmetry of ranks of $\mathrm{R}^{2}$ both in forward and in backward direction are named "association chains". Performance measures, balanced classification rate and the F1-score, showed that St. Nicolas' House Analysis was superior to methods using sophisticated correlation value thresholds and methods based on partial correlations for analyzing bands and hubs (Groth et al. 2019).

The socio-economic variables income, father's education, mother's education, sib size, family member, birth order, government job in the family, house type, toilet type and drinking water were coded for analysis. The most desirable condition was assigned the highest number as code and the least desirable was assigned the lowest number as code.

Therefore, variables such as income, father's education, mother's education, sib size, family member, and birth order increases in parallel with given coding. Families not having a reliable source of income and illiterate parents were coded 0 . At least one government job in the family of participants' were coded as 2 which is desired and not having any government employees in the family was coded 1 . House type was coded with 1, 2 and 3 in increasing order signifying housing condition. Recorded house types were kacha house (wood, mud and bamboo), semi-pacca house (partially concrete) and pacca house (concrete) based on construction materials as given in the parenthesis. Drinking water was coded as 1 if participants have privately managed source of drinking water in their house and in contrast government supply source of drinking water was coded as 2. Similarly, nonwater closet toilets were coded as 1 and water closet toilets were coded as 2 .

\section{Results}

The mean, median, \pm SD of age, HAZ, WAZ, BAZ, and MUACZ along with socio-economic variables family member (FMmember), birth order (BROrder), sib size (SSize), father education (FEDU), mother education (MEDU), house type (HCode), government job in the family (GJob), income, water, and toilet type (Toil) are presented in Table 1. The sample includes both male and female children and adolescents. The valid sample size for WAZ was 273 because the WHO reference for 10 years and above is not available for practical reasons (Table 1).

To assess associations between different variables correlation analysis was conducted and observed correlations were mostly high among similar type of variables. The variables included in the present study were broadly anthropometric variables, socio-economic variables and family statistics. Variables of the same type as anthropometric indices were highly correlated with each other. The observed correlations were low between two different types of variables like socioeconomic variables and family statistics or between anthropometric indices and socio-economic variables (Fig. 1). This is even better represented by SNHA result presented as Fig. 2. The variables having high correlations were connected with each other such as BAZ, WAZ and HAZ which were not associated with any of the socio-economic variables and family statistics. The only anthropometric variable found directly connected with Toil and GJob was MUACZ. PCA with Varimax rotation yield four components which were exclusive to each other (Table 2). The variation explained by $1^{\text {st }}, 2^{\text {nd }}, 3^{\text {rd }}$ and $4^{\text {th }}$ principal component was $16.60 \%, 16.26 \%$,

Table 1. Descriptive statistics of anthropometric indices of nutritional status and socio-economic variables.

\begin{tabular}{|c|c|c|c|c|c|c|}
\hline Variables & $\mathbf{N}$ & Mean & Median & \pm SD & Minimum & Maximum \\
\hline Age (years) & 538 & 10.17 & 10.04 & 3.57 & 2.27 & 18.67 \\
\hline HAZ & 538 & -1.75 & -1.81 & 1.06 & -5.94 & 2.28 \\
\hline WAZ & 273 & -1.19 & -1.15 & 0.97 & -3.70 & 2.09 \\
\hline BAZ & 538 & -0.16 & -0.16 & 0.84 & -4.67 & 2.15 \\
\hline MUACZ & 538 & -0.99 & -1.01 & 0.69 & -3.56 & 1.06 \\
\hline FMmember & 538 & 5.70 & 5.00 & 2.02 & 2.00 & 17.00 \\
\hline BROrder & 538 & 2.41 & 2.00 & 1.73 & 1.00 & 10.00 \\
\hline SSize & 538 & 3.10 & 3.00 & 1.85 & 1.00 & 10.00 \\
\hline FEDU (years) & 538 & 5.22 & 5.00 & 4.05 & 0.00 & 17.00 \\
\hline MEDU (years) & 538 & 3.78 & 3.00 & 3.84 & 0.00 & 15.00 \\
\hline HCode & 538 & 2.12 & 2 & 0.74 & 1.00 & 3.00 \\
\hline GJob & 538 & 1.16 & 1 & 0.36 & 1.00 & 2.00 \\
\hline Income (in ₹) & 538 & 9.19 & 9.00 & 4.88 & 0.00 & 30.00 \\
\hline Water & 538 & 1.64 & 2 & 0.481 & 1.00 & 2.00 \\
\hline Toil & 538 & 1.93 & 2 & 0.26 & 1.00 & 2.00 \\
\hline
\end{tabular}




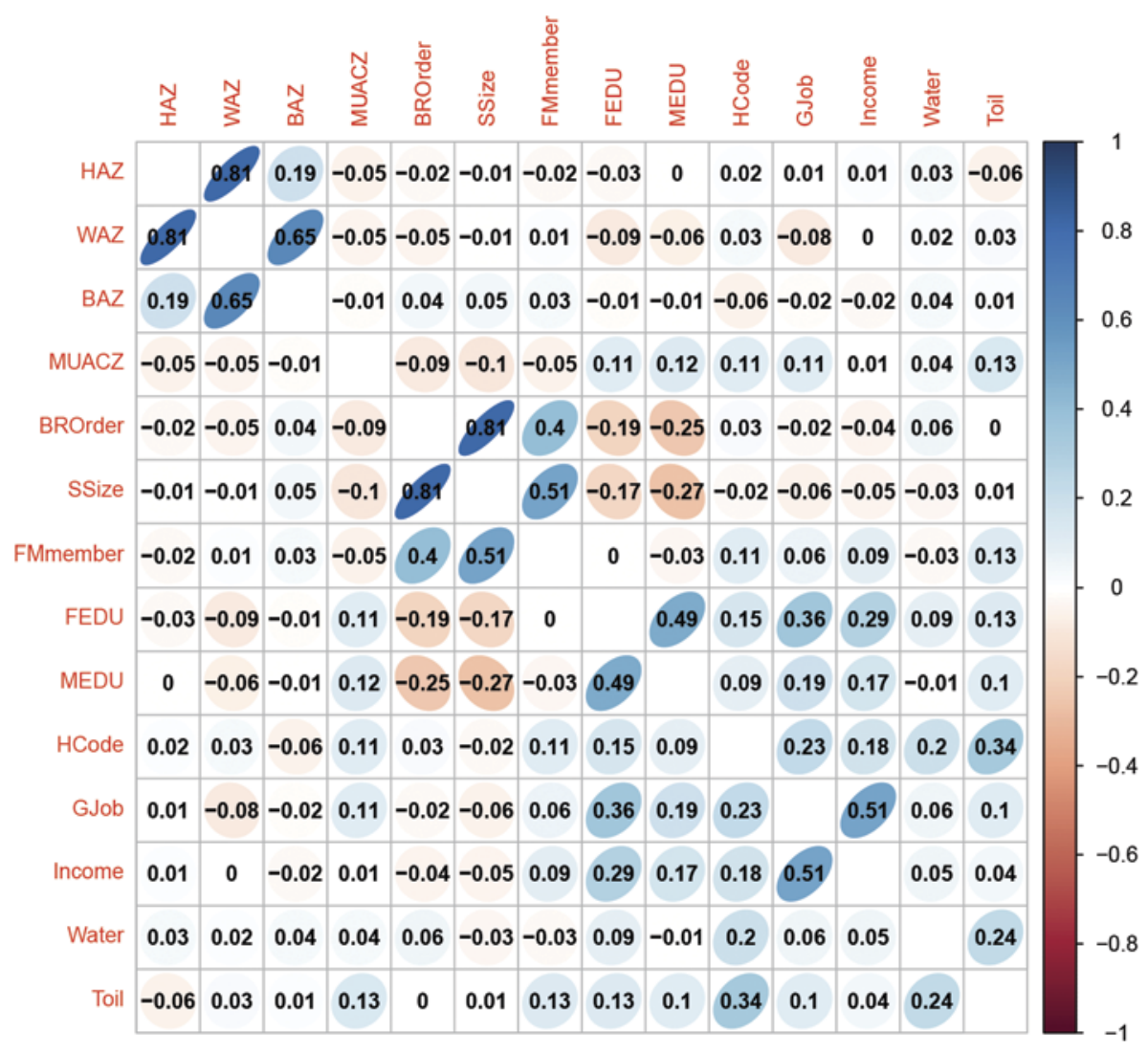

Fig. 1. Result of Correlations.

$15.27 \%$ and $11.97 \%$, respectively. The PCs can be distinguish as "socio-economic variables", "family size", "anthropometry", and "sanitation and MUACZ" as expected. Together the four components explain $60 \%$ of variation in the data. However, the obtained Kaiser-Meyer-Olkin measure of sampling adequacy was below 0.5 , which could be the indication of PCA being not suitable for the present study. The association of MUACZ and BAZ with HAZ was further explained by line fitting of HAZ against each of the variables (Fig. 3 and Fig. 4). The variations explained by MUACZ and BAZ were 0.002 and 0.042 , respectively.

Association plots each of MUACZ and BAZ with HAZ revealed that children and adolescents with normal MUACZ and BAZ were stunted. This will become clear if we draw imaginary lines at $-2.00 \mathrm{Z}$-scores on both the axes (Fig. 3 and Fig. 4). Further, cross- tabulation analysis was obtained for stunting against BAZ and MUACZ. The results of crosstabulations are presented in Table 3. Here stunted children with normal BAZ and MUACZ are of particular interest.

\section{Discussion}

Undernutrition has been considered as a main factor for growth failure among children and adolescents leading to relatively short adult stature. It is believed that chronic undernutrition leads to stunting (low height-for-age Z-score) and acute undernutrition leads to underweight (low weight-forage Z-score). Long term exposures to both diseases and poor nutrition have been regarded as cause of stunting or growth failure (WHO 1995; de Onis \& Branca 2016). However, recent studies have highlighted different phenomenon associated with human growth in height from both contemporary and historic population (Hermanussen \& Scheffler 2016; Hermanussen et al. 2018a).

Previous studies revealed relationship between HAZ and socio-economic variables which is lacking in the present study. Maternal education influenced HAZ of children in Indonesia and Nepal (Devakumar et al. 2014; Groth et al. 2019). The variance in height explained by parental education among the Indonesian children was $3.5 \%-6.5 \%$ using a different analysis technique (Scheffler et al. 2020). Similarly, combined parental education (father and mother) of Bengalee children of Kolkata, India was observed influencing HAZ or height (Scheffler et al. 2018). Among the two cohorts of the study by Dasgupta et al. (2008) only earlier cohorts show the effects of maternal education, expenditure, birth order and sib size on height, but no effect of these variables on height of later cohorts was observed. Another variable strongly influencing height in the study by Dasgupta et al. (2008) was 


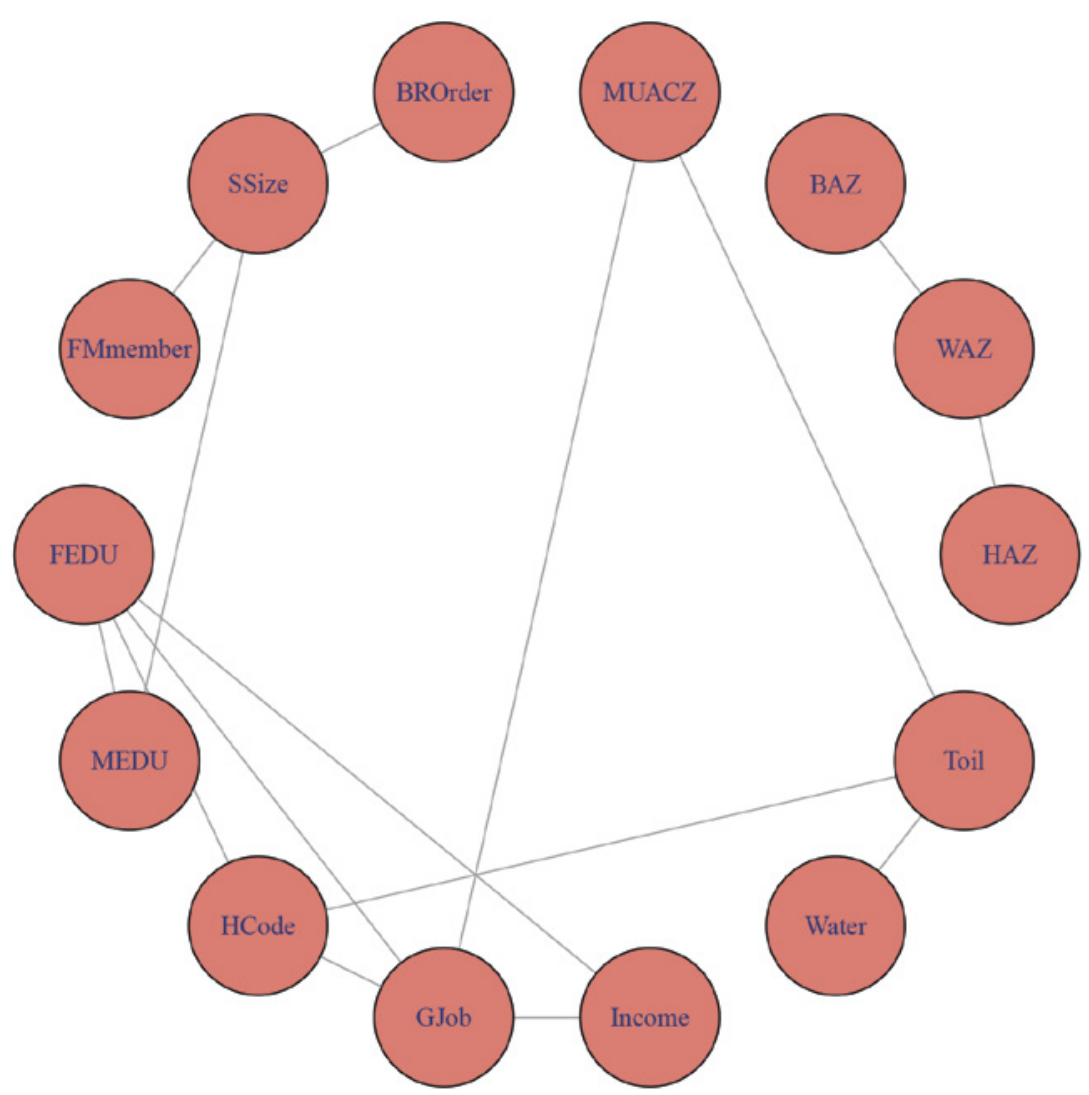

Fig. 2. (SNHA) is a network graph of association chains between the independent variables and the dependent variable HAZ (height-for-age Z-score). Using network graph terminology, each variable is a node in the network and the lines connecting variables are edges. The SNHA finds no edges connecting MUACZ or the socioeconomic variable and family statistic nodes to HAZ.

Table 2. Rotated Component Matrix obtained using Principal component analysis.

\begin{tabular}{|c|c|c|c|c|}
\hline Variables & PC 1 & PC 2 & PC 3 & PC4 \\
\hline Income & 0.809 & & & \\
\hline GJob & 0.772 & & & \\
\hline FEDU & 0.720 & & & \\
\hline MEDU & 0.632 & & & \\
\hline SSize & & 0.923 & & \\
\hline BROrder & & 0.908 & & \\
\hline FMmember & & 0.690 & & \\
\hline WAZ & & & 0.995 & \\
\hline HAZ & & & 0.820 & \\
\hline BAZ & & & 0.662 & \\
\hline Toil & & & & 0.759 \\
\hline Water & & & & 0.669 \\
\hline HCode & & & & 0.632 \\
\hline MUACZ & & & & 0.334 \\
\hline Variance in $\%$ & 16.6 & 16.26 & 15.27 & 11.97 \\
\hline Cumulative \% & 16.6 & 32.87 & 48.14 & 60.10 \\
\hline
\end{tabular}




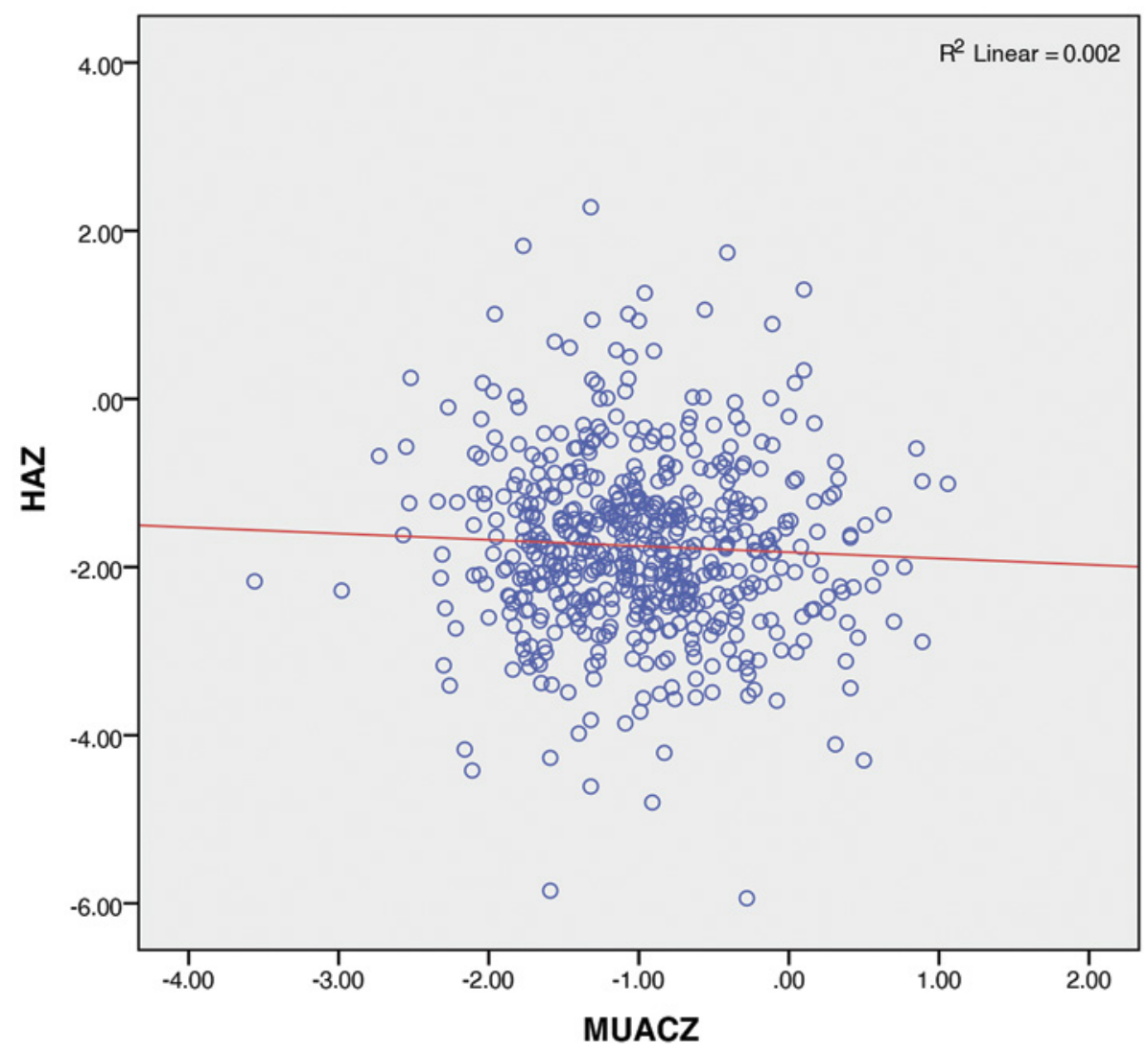

Fig. 3. Regression analysis of MUACZ against HAZ.

monthly family expenditure. In contrast, based on SNHA none of the anthropometric variables have association with socio-economic variables and family statistics in the present study except association of MUACZ with toilet type (Toil) and having government employment in the family (GJob). The idea that poor socio-economic status can also lead to poor nutrition and diseases which in turn can influence height of a growing child (e.g., de Onis 2001; Dasgupta et al. 2008) is not supported by the results of the present study. The observed correlations were high among the similar kind of variables like anthropometric indices, socio-economic variables and family related variables, however not between two different types of variables. There is clearly no connection of socio-economic variables and family statistics with anthropometric indices of growth and nutrition as shown by SNHA excluding MUACZ (Fig. 2).

The SNHA showed links between HAZ, WAZ and BAZ which was further subjected to regression analysis and showed that the variation explained was meager as represented by line fitting of MUACZ and BAZ against HAZ presented separately (Fig. 3 and Fig. 4). The results obtained for children of Indonesia and Kolkata, India using MUAC and skinfolds are same as in the present study (Scheffler et al. 2018; Scheffler et al. 2020). The children and adolescents of the present study and study cited were nutritionally nor- mal. There are Indian studies supporting a modest association of stunting and nutrition (Singh et al. 2017; Anitha et al. 2019). However, more comprehensive studies and reviews of the association of growth and dietary nutrients concludes clear lack of association between nutrition and growth in height (Devakumar et al. 2014; Goudet et al. 2017; Pospisil et al. 2017; Hermanussen et al. 2018a; Hermanussen et al. 2018b). Absence of long lasting influence of nutrition and starvation on height of growing children and adolescents has been substantiated with the evidence from historic and contemporary data (Sguassero et al. 2005; Sguassero et al. 2012; Devakumar et al. 2014; Kristjansson et al. 2015; Hermanussen et al. 2018a; Hermanussen et al. 2018b). The catch-up in height after starvation and re-feeding observed among children living during World War I was larger than that reported from the modern intervention studies and further questions the association of nutrition with growth in height (Hermanussen et al. 2018a; Hermanussen et al. 2018b).

Stunting is decreasing slower than expected which is a concern in the presence of various dietary supplementation programs (de Onis et al. 2012). In India stunting has been a major problem (Bose et al. 2007; Bose et al. 2008; Bose \& Bisai 2008; Gupta \& Kapil 2016; Sinha et al. 2018). Observation on historic data of orphans and underprivileged 


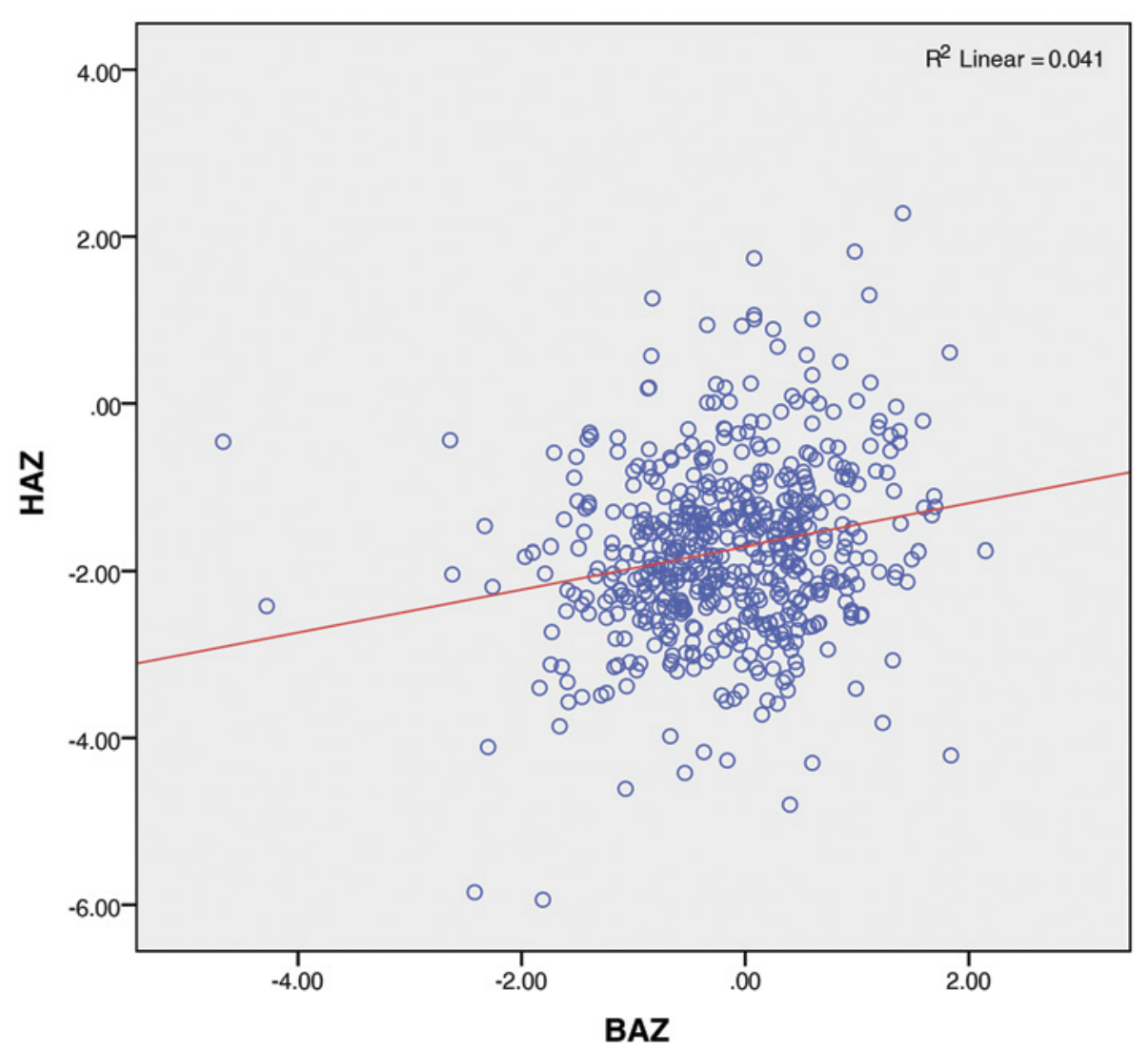

Fig. 4. Regression analysis of $B A Z$ against $H A Z$.

Table 3. Cross-tabulation of normal and thin children by BAZ and MUAZ with stunting, respectively.

\begin{tabular}{|c|c|c|c|c|c|}
\hline \multirow{2}{*}{ HAZ } & \multicolumn{2}{|c|}{ BAZ } & \multicolumn{2}{|c|}{ MUACZ } & \multirow{2}{*}{ All } \\
\hline & Normal & Thinness & Normal & Thinness & \\
\hline Normal & $304(56.5 \%)$ & $3(0.6 \%)$ & $302(56.1 \%)$ & $5(0.9 \%)$ & $307(57.1 \%)$ \\
\hline Stunted & $225(41.8 \%)$ & $6(1.1 \%)$ & $206(38.3 \%)$ & $25(4.6 \%)$ & $231(42.9 \%)$ \\
\hline All & $529(98.3 \%)$ & $9(1.7 \%)$ & $508(94.4 \%)$ & $30(5.6 \%)$ & $538(100.0 \%)$ \\
\hline
\end{tabular}

of Europe after re-feeding was similar to result of interventions among present day children of Asian and African countries i.e. modest effect (Hermanussen et al. 2018a). High stunting rate among the Limboo children and adolescents of the present study whose nutritional status were normal also reflects the same. The results of cross tabulation corroborate the facts even the children with normal MUACZ and BAZ are largely stunted in the present study (Table 3). This may be the suggestion of nutrition reserve in the body has nothing to do with growth in height among these children and adolescents. Similarly stunting can be observed among children and adolescents who are nutritionally normal in India. Stunting may not be due to a problem of nutrition (Hermanussen et al. 2018a; Scheffler et al. 2020). The phenomena associated with human growth both in the contemporary and historic population could be the strategic growth adjustment, as observed in meerkats (Suricata suricatta) and non-human primates (Aßmann \& Hermanussen 2013; Huchard et al. 2016; Hermanussen \& Scheffler 2016).

The proponents of strategic growth adjustment in human consider presence of adequate nutrition, health, and living condition as prerequisites and not true regulators of growth (Bogin et al. 2017; Hermanussen et al. 2018a; Scheffler et al. 2020). The community or social group one belongs is the true regulator of growth, a phenomenon which is called community effect on height. It was shown among children and adolescents from Zurich, Switzerland that during adolescence growth they adjust individual height toward the average height of their peers, which could be their immediate community. Therefore, short adolescents grow more and tall adolescents less as their target is the mean height of the community. As a result, distribution of heights within a community 
clusters around the mean (Aßmann \& Hermanussen 2013). Similar phenomena are reported by a study on Polish children (Koziel \& Gomula 2017; Koziel et al. 2019). This is to say the tall height communities generate tall people and short height communities generate short people. However, switching over is possible which is shown by growth studies among migrants' children (Bogin et al. 2018; Özer \& Scheffler 2018). Large height adjustment among migrants is the result of their integration into the host population, less due to nutrition. This strategic growth adjustment could be a remedy for stunting. Integration, social acceptance and connectedness have been shown responsible for high catch up growth (Hermanussen et al. 2014; Bogin et al. 2018; Özer \& Scheffler 2018; Bents et al. 2018; Lebedeva et al. 2019). The lack of these attributes may results in stunting.

\section{Conclusion}

The children who participated in the present study were nutritionally normal and healthy as assessed using MUACZ and BAZ. Exposure to poor nutrition and infection may not be the primary cause of stunting or growth failure among children and adolescents. The anthropometric indices of nutrition and growth were not found influenced by socioeconomic variables and family statistics in the present study directly. Further, there was lack of association between growth measure by HAZ and nutritional status (MUACZ and BAZ). The presence of stunting in the present study may be due the community effect where the mean height always acts as a magnet around which individual height gets concentrated. Public health workers and researchers should emphasis on the use of community specific growth references. Social integration and acceptance may work as remedies to ease the prevalence of stunting more than nutrition interventions alone.

Acknowledgements: The paper is the result of participation in the International Summer School "Statistical Approaches to Developmental and Growth Data of Children and Adolescents" in Gülpe from 15-20 July 2019. The Summer School was supported by Auxological society (Gesellschaft für Auxologie), the Society of Anthropology (Gesellschaft für Anthropologie) and University of Potsdam, Germany without which this paper would not have been possible. The children and adolescents, as well as their parents and teachers, are acknowledged for their participation in the study. Sincere appreciation is extended to Ganesh Kumar Subba for support to the first author during fieldwork. Financial assistance in the form of a UGC-NET Fellowship [\{F.15-6(Dec., 2011)/2012(NET) dated 27.07.2012\}], to the first author is also acknowledged.

\section{References}

Anitha, S., Kane-Potaka, J., Tsusaka, T. W., Tripathi, D., Upadhyay, S., Kavishwar, A., ... Nedumaran, S. (2019). Acceptance and Impact of Millet-Based Mid-Day Meal on the Nutritional Status of Adolescent School Going Children in a Peri Urban Region of Karnataka State in India. Nutrients, 11(9), E2077. https://doi. org/10.3390/nu11092077 PMID:31484377

Aßmann, C., \& Hermanussen, M. (2013). Modeling determinants of growth: Evidence for a community-based target in height? Pediatric Research, 74(1), 88-95. https://doi.org/10.1038/ pr.2013.50 PMID:23493166

Bents, D., Groth, D., \& Satake, T. (2018). The secular trend and network effects on height of male Japanese students from 1955 to 2015. Anthropologischer Anzeiger, 74(5), 423-429. https:// doi.org/10.1127/anthranz/2018/0838 PMID:29668008

Bogin, B., Scheffler, C., \& Hermanussen, M. (2017). Global effects of income and income inequality on adult height and sexual dimorphism in height. American Journal of Human Biology, 29(2), e22980. https://doi.org/10.1002/ajhb.22980 PMID: 28199042

Bogin, B., Hermanussen, M., \& Scheffler, C. (2018). As tall as my peers - similarity in body height between migrants and hosts. Anthropologischer Anzeiger, 74(5), 365-376. https://doi. org/10.1127/anthranz/2018/0828 PMID:29328347

Bose, K., Biswas, S., Bisai, S., Ganguli, S., Khatun, A., Mukhopadhyay, A., \& Bhadra, M. (2007). Stunting, underweight and wasting among Integrated Child Development Services (ICDS) scheme children aged 3-5 years of Chapra, Nadia District, West Bengal, India. Maternal and Child Nutrition, 3(3), 216-221. https://doi.org/10.1111/j.17408709.2007.00099.x PMID:17539890

Bose, K., \& Bisai, S. (2008). Prevalence of underweight and stunting among school children in West Bengal. [No abstract available.]. Indian Journal of Pediatrics, 75(12), 1272. https://doi. org/10.1007/s12098-008-0167-6 PMID:18810360

Bose, K., Bisai, S., Chakraborty, J., Datta, N., \& Banerjee, P. (2008). Extreme levels of underweight and stunting among preadolescent children of low socioeconomic class from Madhyamgram and Barasat, West Bengal, India. Collegium Antropologicum, 32(1), 73-77. PMID:18494191

Census of India (2011): Government of India. http://www.census india.gov.in/

Chakraborty, R., Bose, K., \& Koziel, S. (2011). Use of mid-upper arm circumference in determining undernutrition and illness in rural adult Oraon men of Gumla District, Jharkhand, India. Rural and Remote Health, 11(3), 1754. PMID:21882889

Chaput, J. P., Katzmarzyk, P. T., Barnes, J. D., Fogelholm, M., Hu, G., Kuriyan, R., ... Tremblay, M. S., \& the ISCOLE Research Group. (2017). Mid-upper arm circumference as a screening tool for identifying children with obesity: A 12-country study. Pediatric Obesity, 12(6), 439-445. https://doi.org/10.1111/ ijpo.12162 PMID:27238202

Chirande, L., Charwe, D., Mbwana, H., Victor, R., Kimboka, S., Issaka, A. I., ... Agho, K. E. (2015). Determinants of stunting and severe stunting among under-fives in Tanzania: Evidence from the 2010 cross-sectional household survey. $B M C$ Pediatrics, 15(1), 165. https://doi.org/10.1186/s12887-0150482-9 PMID:26489405 
Cole, T. J., Bellizzi, M. C., Flegal, K. M., \& Dietz, W. H. (2000). Establishing a standard definition for child overweight and obesity worldwide: International survey. BMJ (Clinical Research Ed.), 320(7244), 1240-1243. https://doi.org/10.1136/bmj. 320.7244.1240 PMID:10797032

Cole, T. J., Flegal, K. M., Nicholls, D., \& Jackson, A. A. (2007). Body mass index cut offs to define thinness in children and adolescents: International survey. BMJ (Clinical Research Ed.), 335(7612), 194-2002. https://doi.org/10.1136/bmj.39238. 399444.55 PMID:17591624

Craig, E., Bland, R., Ndirangu, J., \& Reilly, J. J. (2014). Use of mid-upper arm circumference for determining overweight and overfatness in children and adolescents. Archives of Disease in Childhood, 99(8), 763-766. https://doi.org/10.1136/archdischild2013-305137 PMID:24890851

Dasgupta, P., Saha, R., \& Nubé, M. (2008). Changes in body size, shape and nutritional status of middle-class Bengali boys of Kolkata, India, 1982-2002. Economics and Human Biology, 6(1), 75-94. https://doi.org/10.1016/j.ehb.2007.05.001 PMID: 17618843

de Onis, M., Yip, R., \& Mei, Z. (1997). The development of MUAC-for-age reference data recommended by a WHO Expert Committee. Bulletin of the World Health Organization, 75(1), 11-18. PMID:9141745

de Onis, M., Dasgupta, P., Saha, S., Sengupta, D., \& Blössner, M. (2001). The National Center for Health Statistics reference and the growth of Indian adolescent boys. The American Journal of Clinical Nutrition, 72, 248-253. https://doi.org/10.1093/ajcn/ 74.2.248 PMID:11470728

de Onis, M., Onyango, A. W., Borghi, E., Siyam, A., Nishida, C., \& Siekmann, J. (2007). Development of a WHO growth reference for school-aged children and adolescents. Bulletin of the World Health Organization, 85(9), 660-667. https://doi.org/10.2471/ BLT.07.043497 PMID:18026621

de Onis, M., Blössner, M., \& Borghi, E. (2012). Prevalence and trends of stunting among pre-school children, 1990-2020. Public Health Nutrition, 15(1), 142-148. https://doi.org/ 10.1017/S1368980011001315 PMID:21752311

de Onis, M., \& Branca, F. (2016). Childhood stunting: A global perspective. Maternal and Child Nutrition, 12(Suppl 1), 12-26. https://doi.org/10.1111/mcn.12231 PMID:27187907

Demirchyan, A., Petrosyan, V., Sargsyan, V., \& Hekimian, K. (2016). Predictors of Stunting Among Children Ages 0 to 59 Months in a Rural Region of Armenia. Journal of Pediatric Gastroenterology and Nutrition, 62(1), 150-156. https://doi. org/10.1097/MPG.0000000000000901 PMID:26192698

Devakumar, D., Chaube, S. S., Wells, J. C., Saville, N. M., Ayres, J. G., Manandhar, D. S., ... Osrin, D. (2014). Effect of antenatal multiple micronutrient supplementation on anthropometry and blood pressure in mid-childhood in Nepal: Follow-up of a double-blind randomised controlled trial. The Lancet. Global Health, 2(11), e654-e663. https://doi.org/10.1016/S2214109X(14)70314-6 PMID:25442690

Dorjee, B. (2015). Thinness and Overweight among Children belonging to Bengalee Population Aged 3-10 years. South Asian Anthropologist, 15(2), 135-144.

Dorjee, B., Das, S., Mondal, N., \& Sen, J. (2015). Dermatoglyphic variation among the Limboo of Sikkim, India. Homo, 66(5), 455-470. https://doi.org/10.1016/j.jchb.2015.02.010 PMID: 26142831
Frisancho, A. R. (1974). Triceps skin fold and upper arm muscle size norms for assessment of nutrition status. The American Journal of Clinical Nutrition, 27(10), 1052-1058. https://doi. org/10.1093/ajen/27.10.1052 PMID:4419774

Frisancho, R. (2008). Anthropometric Standards: An Interactive Nutritional Reference of Body Size and Body Composition for Children and Adults ( $2^{\text {nd }}$ ed.). Ann Arbor: University of Michigan Press. https://doi.org/10.3998/mpub.93311

Goudet, S., Griffiths, P., Bogin, B., \& Madise, N. (2017). Interventions to tackle malnutrition and its risk factors in children living in slums: A scoping review. [Review]. Annals of Human Biology, 44(1), 1-10. https://doi.org/10.1080/03014460 .2016.1205660 PMID:27356853

Groth, D., Scheffler, C., \& Hermanussen, M. (2019). Body height in stunted Indonesian children depends directly on parental education and not via a nutrition mediated pathway - Evidence from tracing association chains by St. Nicolas House Analysis. Anthropologischer Anzeiger, 76(5), 445-451. https://doi.org/ 10.1127/anthranz/2019/1027 PMID:30990515

Gupta, A., \& Kapil, U. (2016). Reduction in the Prevalence of Underweight, Stunting and Wasting in Selected States of India. Indian Journal of Pediatrics, 83(12-13), 1488-1490. https://doi. org/10.1007/s12098-016-2174-3 PMID:27287775

Harries, A. D., \& Rhodes, J. (1985). Efficiency of anthropometric indicators in the assessment of protein nutrition in Crohn's disease. Human Nutrition Clinical Nutrition, 39C, 155-158. PMID:4019265

Hermanussen, M., Alt, C., Staub, K., Aßmann, C., \& Groth, D. (2014). The impact of physical connectedness on body height in Swiss conscripts. Anthropologischer Anzeiger, 71(4), 313-327. https://doi.org/10.1127/0003-5548/2014/0466 PMID:25774949

Hermanussen, M., \& Scheffler, C. (2016). Stature signals status: The association of stature, status and perceived dominance - a thought experiment. Anthropologischer Anzeiger, 73(4), 265-274. https:// doi.org/10.1127/anthranz/2016/0698 PMID:27643683

Hermanussen, M., Bilogub, M., Lindl, A. C., Harper, D., Mansukoski, L., \& Scheffler, C. (2018a). Weight and height growth of malnourished school-age children during re-feeding. Three historic studies published shortly after World War I. European Journal of Clinical Nutrition, 72(12), 1603-1619. https://doi.org/10.1038/s41430-018-0274-z PMID:30166640

Hermanussen, M., Bogin, B., \& Scheffler, C. (2018b). Stunting, starvation and refeeding: A review of forgotten $19^{\text {th }}$ and early $20^{\text {th }}$ century literature. Acta Paediatrica (Oslo, Norway), 107(7), 1166-1176. https://doi.org/10.1111/apa.14311 PMID:29526048

Huchard, E., English, S., Bell, M. B., Thavarajah, N., \& CluttonBrock, T. (2016). Competitive growth in a cooperative mammal. Nature, 533(7604), 532-534. https://doi.org/10.1038/nature 17986 PMID:27225127

James, W. P., Mascie-Taylor, G. C., Norgan, N. G. Bistrian, B. R., Shetty, P. S., \& Ferro-Luzzi, A. (1994). The value of arm circumference measurements in assessing chronic energy deficiency in Third World adult. European Journal of Clinical Nutrition, 48(12), 883-894. PMID:7889897

Jaswant, S., \& Nitish, M. (2014). Use of upper-arm anthropometry as measure of body-composition and nutritional assessment in children and adolescents (6-20 years) of Assam, Northeast India. Ethiopian Journal of Health Sciences, 24(3), 243-252. https://doi.org/10.4314/ejhs.v24i3.8 PMID:25183931

Jelliffe, D. B. (1966). Assessment of the nutritional status of the community. Monograph. Series No. 53. Geneva: WHO. 
Kinyoki, D. K., Kandala, N. B., Manda, S. O., Krainski, E. T., Fuglstad, G. A., Moloney, G. M., ... Noor, A. M. (2016). Assessing comorbidity and correlates of wasting and stunting among children in Somalia using cross-sectional household surveys: 2007 to 2010. BMJ (Clinical Research Ed.), 6(3), e009854. https://doi.org/10.1136/bmjopen-2015-009854 PMID: 26962034

Koziel, S., \& Gomula, A. (2017). Variation of height and BMI within school classes in 14-year-old children. Anthropologischer Anzeiger, 74(1), 77-80. https://doi.org/10.1127/anthranz/2017/ 0702 PMID:28362020

Koziel, S., Zaręba, M., Bielicki, T., Scheffler, C., \& Hermanussen, M. (2019). Social mobility of the father influences child growth: A three-generation study. American Journal of Human Biology, 31(4), e23270. https://doi.org/10.1002/ajhb.23270 PMID: 31190434

Kristjansson, E., Francis, D. K., Liberato, S., Benkhalti Jandu, M., Welch, V., Batal, M., ... Petticrew, M. (2015). Food supplementation for improving the physical and psychosocial health of socio-economically disadvantaged children aged three months to five years. Cochrane Database of Systematic Reviews, CD009924(3), CD009924. https://doi.org/10.1002/14651858. CD009924.pub2 PMID:25739460

Lebedeva, L., Groth, D., Hermanussen, M., Scheffler, C., \& Godina, E. (2019). The network effects on conscripts' height in the central provinces of Russian empire in the middle of XIX century at the beginning of XX century. Anthropologischer Anzeiger, 76(5), 371-377. https://doi.org/10.1127/anthranz/2019/0984 PMID:30994699

Neufeld, L. M., \& Osendarp, S. J. (2014). Global, regional and country trends in underweight and stunting as indicators of nutrition and health of populations. Nestlé Nutrition Institute Workshop Series, 78, 11-19. https://doi.org/10.1159/000354930 PMID:24504202

Özer, A., \& Scheffler, C. (2018). Affinity to host population stimulates physical growth in adult offspring of Turkish migrants in Germany. Anthropologischer Anzeiger, 74(5), 359-364. https:// doi.org/10.1127/anthranz/2018/0825 PMID:29349478

Reilly, J. J. (2017). Mid-upper arm circumference (MUAC): New applications for an old measure. Archives of Disease in Childhood, 102(1), 1-2. https://doi.org/10.1136/archdischild-2016-311682 PMID:27831914

Scheffler, C., Krützfeldt, L. M., Dasgupta, P., \& Hermanussen, M. (2018). No association between fat tissue and height in 5019 children and adolescents, measured between 1982 and in 2011 in Kolkata/India. Anthropologischer Anzeiger, 74(5), 403-411. https://doi.org/10.1127/anthranz/2018/0827 PMID:29543314
Scheffler, C., Hermanussen, M., Bogin, B., Liana, D. S., Taolin, F., Cempaka, P. M. V. P., ... Pulungan, A. (2020). Stunting is not a synonym of malnutrition. European Journal of Clinical Nutrition, 74(3), 377-386. https://doi.org/10.1038/s41430-0190439-4 PMID:31142828

Sen, J., Mitra, K., \& Dey, S. (2010). Study on mid-upper arm circumference with special reference to under-nutrition. South Asian Anthropologist, 10(2), 135-145.

Sguassero, Y., de Onis, M., \& Carroli, G. (2005). Communitybased supplementary feeding for promoting the growth of young children in developing countries. Cochrane Database of Systematic Reviews, 2005(4), CD005039. https://doi. org/10.1002/14651858.CD005039.pub2 PMID:16235389

Sguassero, Y., de Onis, M., Bonotti, A. M., \& Carroli, G. (2012). Community-based supplementary feeding for promoting the growth of children under five years of age in low and middle income countries. Cochrane Database of Systematic Reviews, CD005039(6), CD005039. https://doi.org/10.1002/14651858. CD005039.pub3 PMID:22696347

Singh, A., Upadhyay, A. K., \& Kumar, K. (2017). Birth Size, Stunting and Recovery from Stunting in Andhra Pradesh, India: Evidence from the Young Lives Study. Maternal and Child Health Journal, 21(3), 492-508. https://doi.org/10.1007/ s10995-016-2132-8 PMID:27456305

Sinha, R. K., Dua, R., Bijalwan, V., Rohatgi, S., \& Kumar, P. (2018). Determinants of Stunting, Wasting, and Underweight in Five High-Burden Pockets of Four Indian States. Indian Journal of Community Medicine, 43(4), 279-283. https://doi. org/10.4103/ijcm.IJCM 151_18 PMID:30662180

Ulijaszek, S. J., \& Kerr, D. A. (1999). Anthropometric measurement error and the assessment of nutritional status. British Journal of Nutrition, 82(3), 165-177. https://doi.org/10.1017/ S0007114599001348 PMID:10655963

Weiner, J. S., \& Lourie, J. A. (1981). Practical human biology. London: Academic Press.

WHO. (1995): Physical status: The use and interpretation of anthropometry. Technical Report series, 854, 1-452. Geneva: World Health Organization.

Manuscript received: 09 October 2019

Revisions requested: 28 November 2019

Revised version received: 17 January 2020

Accepted: 17 January 2020 